\title{
The Newmarket pump: a new suction pump for external negative pressure ventilation
}

\author{
WJM KINNEAR, JM SHNEERSON \\ From Newmarket General Hospital, Newmarket, Suffolk
}

\begin{abstract}
A new electronically controlled pump has been developed for use with a cuirass in providing external negative pressure ventilation. It is smaller, lighter, and more versatile than currently available pumps and operates on a servo principle. A rotary valve between the pump and the cuirass varies the rate of extraction of air from the cuirass. The pressure within the cuirass is sensed by a pressure transducer, and the output of this is used to control the position of the rotary valve by means of a motor so that the pressure within the cuirass follows a predetermined half sine wave pattern. The respiratory rate varies from 10 to 30 per minute and the inspiratory to expiratory time (I/E) ratio from $3: 2$ to $2: 3$. Inspiratory pressure varies from 0 to $-50 \mathrm{~cm}_{2} \mathrm{O}$ and an expiratory pressure of 0 to $+50 \mathrm{~cm} \mathrm{H} \mathrm{H}_{2} \mathrm{O}$ can be imposed. The performance of the new pump was assessed in 21 patients with nocturnal hypoxaemia who were accustomed to external negative pressure ventilation. The mean tidal volume achieved increased with increase in cuirass suction pressure, and changing the $\mathrm{I} / \mathrm{E}$ ratio from $1: 1$ to $3: 2$ produced a small increase at a cuirass negative pressure at $20 \mathrm{~cm}$ water. Comparison of the Newmarket pump with the Cape pump in 14 patients showed that similar tidal volumes were achieved. Overnight monitoring of cuirass pressure in one patient showed more even control of peak negative pressure with the Newmarket pump than with the Cape pump. Ten pumps are in use in patients' homes; five have been in service for more than six months and no important problems have been encountered. The new pump seems to offer advantages that make external negative pressure ventilation more acceptable.
\end{abstract}

Artificial ventilation, by creating a negative pressure around the thorax and abdomen, is effective in maintaining adequate ventilation at night in patients with scoliosis, ${ }^{1}$ thoracoplasty, ${ }^{2}$ respiratory muscle weakness, ${ }^{3}$ central sleep apnoea, ${ }^{4}$ and airflow obstruction. $^{5}$ Ventilation is achieved by creating an intermittent negative pressure within a rigid airtight shell that surrounds either the whole body caudal to the neck, as in a tank respirator, or only the thorax and abdomen.

The use of these smaller shells in the form of a cuirass or in conjunction with an airtight suit has many potential advantages, particularly for long term nocturnal ventilatory support in the patient's home. Among the factors that have limited the widespread use of this method are the large size and

Address for reprint requests: Dr WJM Kinnear, Newmarket General Hospital, Newmarket, Suffolk CB8 7JG.

Accepted 3 April 1985 lack of versatility of the currently available pumps for developing the negative pressure. We describe a new pump that overcomes some of these defects and compare it with the standard pump used in the United Kingdom.

\section{Technical features}

The Newmarket pump (fig 1) has been developed in conjunction with Si-Plan Electronics Research Ltd (Avenue Farm Industrial Estate, Stratford upon Avon, Warwickshire CV3 70HP).

The air pump works on a principle similar to that of a domestic vacuum cleaner, although it runs at a lower speed to keep noise to a minimum. It has a capacity of 1000 litres per minute. The negative pressure side of the air pump is opened intermittently by a rotary valve to the cuirass or similar device used to provide assisted ventilation. This valve is mechanically actuated by an electric motor and associated gearbox. When the valve opens, air is 


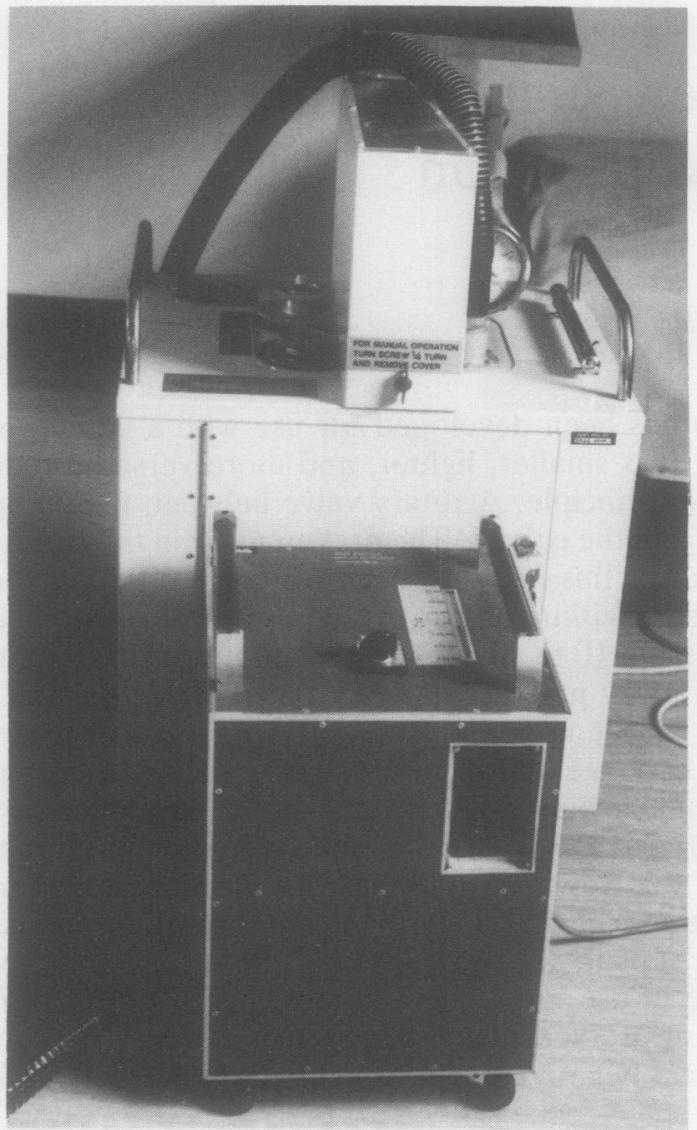

Fig 1 The Newmarket pump (foreground) seen with the Cape cuirass pump (background) for comparison.

sucked out of the cuirass, creating a negative pressure within the cuirass shell and resulting in inspiration. When the valve is closed, air flows into the cuirass from the atmosphere and the pressure within the cuirass returns to the ambient pressure. Expiration occurs by passive elastic recoil of the chest, but the valve can be rotated so that the cuirass equilibrates with the positive pressure side of the air pump to assist expiration. The control electronics, pressure transducer, and main air pump form a feedback control loop (fig 2).

The electrical output of the signal generator (normally a half sine wave) causes the rotary valve to open and the pressure within the pump chamber to rise as air flows in from the cuirass. The resultant pressure change is detected by a pressure transducer and converted to an electrical signal that is continuously subtracted from the original signal of the signal generator. The rotary valve takes up a position that maintains equilibrium between the output

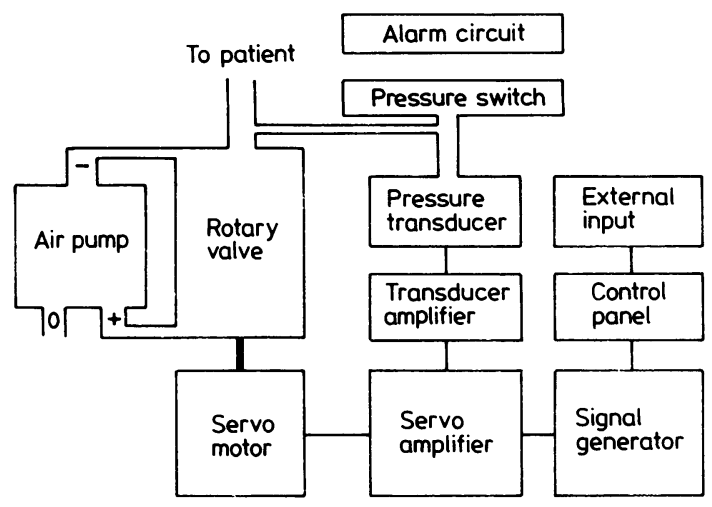

Fig 2 Block diagram of the Newmarket pump.

from the signal generator and the feedback from the pressure transducer. This ensures that the pressure variation within the cuirass is a smooth half sine wave, even in the face of considerable and variable air leaks between the patient and the cuirass shell.

An optional external input plug enables waveforms other than sinewave to be used, and this may also be used for patient triggering of the respiratory cycle with nasal pressure transducers or impedance plethysmography. The external input facility may be used to link two pumps together for use with larger external negative pressure devices. The pump has four control dials: (1) negative pressure: this may be used to vary the inspiratory pressure from zero to $-50 \mathrm{~cm} \mathrm{H}_{2} \mathrm{O}$. (2) Positive pressure: this alters the expiratory pressure from zero to +50 $\mathrm{cm} \mathrm{H}_{2} \mathrm{O}$. (3) Respiratory frequency: this is continuously variable from 10 to 30 cycles per minute. (4) Inspiratory-expiratory ratio: this is continuously variable from $2: 3$ to $3: 2$.

The control panel is situated on the side of the pump, and an on-off switch is readily accessible on the top of the pump. Negative and positive pressure are displayed on a light emitting diode bar graph display on the top of the pump.

An alarm sounds to indicate mains failure, a pump fault, or inadequate pressure generation as a result of major air leakage either between the patient and the cuirass shell or in the connecting tubing.

\section{Methods}

Twenty one patients with nocturnal hypoxaemia were fitted with Vitrathine cuirass shells constructed individually for each patient. All of the patients were accustomed to external negative pressure ventilation. Details of the patients and the contribution of different factors to the nocturnal hypoxaemia in 
each patient are shown in table $1 . \mathrm{FEV}_{1}$ and forced vital capacity were measured with a dry spirometer (Vitalograph) and total lung capacity was measured by helium dilution. Tidal volumes were taken as the mean of five breaths measured with a water sealed spirometer after the patient had become accustomed to the mouthpiece and reached a steady state at each pump setting. The pressure inside the cuirass shell was measured with a pressure transducer (KDG Instruments) connected by $20 \mathrm{~cm}$ of $4 \mathrm{~mm}$ diameter tubing to the cuirass.

The Newmarket pump was set at a rate of 15 breaths per minute with inspiratory-expiratory (I:E) ratios of $1: 1$ and 3:2. It was compared in 14 subjects with the standard pump used in Britain for this form of ventilation, the Cape cuirass pump. The Cape pump can be seen in the background of figure 1 ; and details of the pump are given in table 2 . It is a bellows pump with a stroke volume of 17.6 litres and the suction pressure generated is controlled by a valve; when this opens it alters the proportion of each stroke that is drawn from the cuirass. The I:E ratio is fixed at $1: 2$ and the rate can be set at 13,16 , 19,22 , or 25 cycles per minute by changing the belt on a pulley system inside the pump cabinet. In this study the Cape pump was set at 16 breaths per minute with a fixed I:E ratio of $1: 2$. Statistical comparisons were made with Student's paired $t$ test.
Results

The tidal volumes at each pressure for $\mathrm{I}: \mathrm{E}$ ratios of 1:1 and 3:2 with the Newmarket pump in the 21 subjects are shown in figure 3 ; there was no significant advantage in prolonging the $\mathrm{I}: \mathrm{E}$ ratio at a suction pressure of $10 \mathrm{~cm} \mathrm{H} \mathrm{H}_{2} \mathrm{O}$, but at $20 \mathrm{~cm} \mathrm{H}$ this produced a $10.6 \%$ greater tidal volume, which was significantly different $(\mathrm{p}<0.01)$. At 3.0 and 40 cm $\mathrm{H}_{2} \mathrm{O}$ suction pressure the tidal volumes-achieved were $13.2 \%$ and $8.7 \%$ greater with an I:E ratio of $3: 2$, but these differences were not significant since we were unable to achieve this pressure in six subjects at $30 \mathrm{~cm} \mathrm{H}_{2}$ and in 10 subjects at $40 \mathrm{~cm} \mathrm{H}_{2} \mathrm{O}$. A further three subjects at $30 \mathrm{~cm} \mathrm{H}_{2} \mathrm{O}$ and four subjects at $40 \mathrm{~cm} \mathrm{H}_{2} \mathrm{O}$ were unable to tolerate the pressure for a sufficient length of time for satisfactory volume traces to be obtained. These increases in tidal volume with a higher I:E ratio were seen even when patients were considered separately in groups with predominantly chest wall, muscle, or airway disease.

Figure 4 compares the tidal volumes achieved with the Cape pump and the Newmarket pump with the I:E ratio of the latter set at $1: 1$. Fourteen subjects were compared at 10 and $20 \mathrm{~cm} \mathrm{H}_{2} \mathrm{O}$ suction pressure. Ten patients were studied at $30 \mathrm{~cm} \mathrm{H}_{2} \mathrm{O}$ as this pressure could not be achieved with both pumps

Table 1 Lung function and cause of respiratory failure in 21 subjects

\begin{tabular}{|c|c|c|c|c|c|c|c|c|c|c|}
\hline $\begin{array}{l}\text { Patient } \\
\text { No }\end{array}$ & Sex & Age & $\begin{array}{l}F E V_{1} \\
(m l)\end{array}$ & $\begin{array}{l}F V C \\
(m l)\end{array}$ & $\begin{array}{l}T L C \\
(m l)\end{array}$ & Scoliosis & $\begin{array}{l}\text { Thoraco- } \\
\text { plasty }\end{array}$ & $\begin{array}{l}\text { Muscle } \\
\text { weakness }\end{array}$ & $\begin{array}{l}\text { Airflow } \\
\text { obstruction }\end{array}$ & $\begin{array}{l}\text { Central } \\
\text { apnoea }\end{array}$ \\
\hline $\begin{array}{r}1 \\
2 \\
3 \\
4 \\
5 \\
6 \\
7 \\
8 \\
9 \\
10 \\
11 \\
12 \\
13 \\
14 \\
15 \\
16 \\
17 \\
18 \\
19 \\
20 \\
21\end{array}$ & $\begin{array}{l}\mathbf{M} \\
\mathbf{F} \\
\mathbf{M} \\
\mathbf{M} \\
\mathbf{M} \\
\mathbf{M} \\
\mathbf{M} \\
\mathbf{M} \\
\mathbf{F} \\
\mathbf{M} \\
\mathbf{M} \\
\mathbf{M} \\
\mathbf{M} \\
\mathbf{M} \\
\mathbf{F} \\
\mathbf{F} \\
\mathbf{F} \\
\mathbf{M} \\
\mathbf{F} \\
\mathbf{M} \\
\mathbf{M}\end{array}$ & $\begin{array}{l}61 \\
58 \\
46 \\
53 \\
38 \\
38 \\
15 \\
12 \\
21 \\
78 \\
36 \\
72 \\
68 \\
54 \\
71 \\
51 \\
70 \\
59 \\
53 \\
56 \\
67\end{array}$ & $\begin{array}{r}850 \\
600 \\
800 \\
350 \\
750 \\
1000 \\
1050 \\
300 \\
1000 \\
1200 \\
1400 \\
1000 \\
650 \\
1250 \\
700 \\
400 \\
500 \\
490 \\
350 \\
1300 \\
800\end{array}$ & $\begin{array}{r}1150 \\
1050 \\
900 \\
650 \\
750 \\
1200 \\
2550 \\
440 \\
1100 \\
1950 \\
1400 \\
1350 \\
2050 \\
2200 \\
1500 \\
720 \\
1500 \\
1310 \\
1400 \\
2000 \\
2100\end{array}$ & $\begin{array}{r}2300 \\
1990 \\
1230 \\
1490 \\
1450 \\
2110 \\
2970 \\
850 \\
1840 \\
2710 \\
2920 \\
2420 \\
5550 \\
3820 \\
4800 \\
1680 \\
4880 \\
5700 \\
3970 \\
2830 \\
6600\end{array}$ & $\begin{array}{l}+++ \\
+++ \\
+++ \\
+++ \\
+++ \\
++ \\
+\end{array}$ & $\begin{array}{l}+++ \\
+++ \\
+++ \\
+++ \\
+++\end{array}$ & $\begin{array}{l}++ \\
\\
++ \\
++ \\
+++ \\
+++ \\
++ \\
+++ \\
+++\end{array}$ & $\begin{array}{l} \\
+++ \\
++ \\
++ \\
++ \\
+++ \\
+++ \\
+++ \\
+ \\
++\end{array}$ & $\begin{array}{l}++ \\
+++\end{array}$ \\
\hline
\end{tabular}

+ Mild; ++ moderate; +++ severe.

Table 2 Details of Newmarket and Cape cuirass pumps

\begin{tabular}{|c|c|c|c|c|c|c|}
\hline Pump & $\begin{array}{l}\text { Weight } \\
(\mathrm{kg})\end{array}$ & $\frac{\text { Height }}{(\mathrm{cm})}$ & Depth & Width & $\begin{array}{l}\text { Rate } \\
\text { (cycles/min) }\end{array}$ & $\begin{array}{l}\text { Inspiratory- } \\
\text { expiratory ratio }\end{array}$ \\
\hline $\begin{array}{l}\text { Newmarket } \\
\text { Cape }\end{array}$ & $\begin{array}{l}32.5 \\
72.0\end{array}$ & $\begin{array}{l}470 \\
790\end{array}$ & $\begin{array}{l}395 \\
610\end{array}$ & $\begin{array}{l}350 \\
520\end{array}$ & $\begin{array}{l}10-30 \\
13,16,19,22,25\end{array}$ & $\begin{array}{l}2: 3-3: 2 \\
1: 2\end{array}$ \\
\hline
\end{tabular}




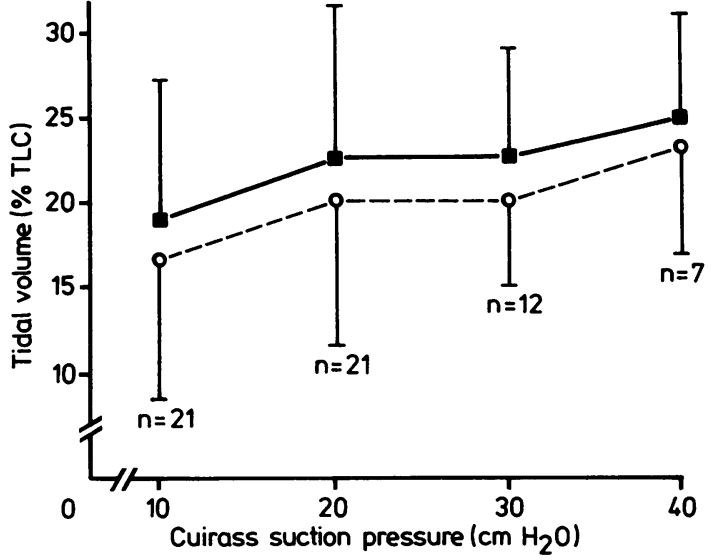

Fig 3 Tidal volumes achieved at different suction pressures with the Newmarket pump, at inspiratory-expiratory ratios of 1:1 (O) and 3:2 (ם), expressed as means with one standard deviation. TLC - total lung capacity.

in two patients and two more patients were unable to tolerate it. Six patients were studied at a negative pressure of $40 \mathrm{~cm} \mathrm{H} \mathrm{H}_{2} \mathrm{O}$ as this pressure could not be achieved in five patients and a further three were unable to tolerate it. There was no significant difference between the Cape and Newmarket pumps at any suction pressure.

When the Cape was compared with the Newmarket pump with an I:E ratio of 3:2 for the latter there was no significant difference at $10 \mathrm{~cm} \mathrm{H}_{2} \mathrm{O}$ suction pressure, but at $20 \mathrm{~cm} \mathrm{H}_{2} \mathrm{O}$ the Newmarket pump produced a slightly greater tidal volume (increase of

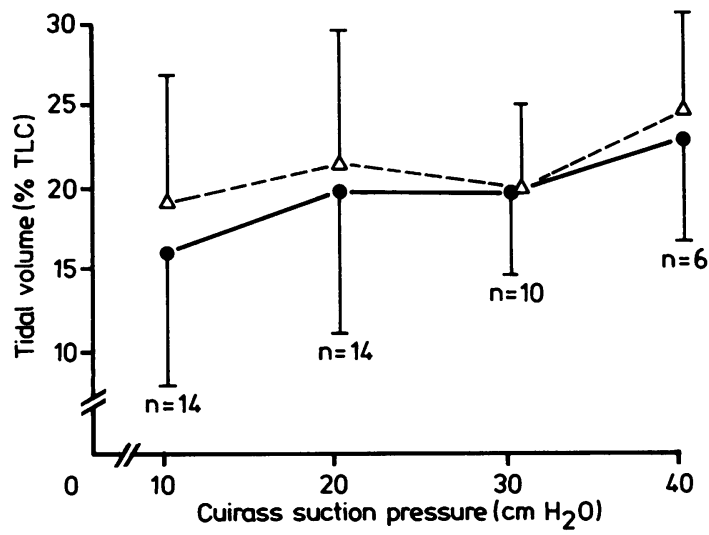

Fig 4 Tidal volumes achieved at different suction pressures with the Newmarket pump, at an inspiratory-expiratory ratio of 1:1 (O), and the Cape cuirass pump ( $\triangle$ ), expressed as means with one standard deviation.
$2.6 \% ; \mathrm{p}<0.05)$. At higher suction pressures the Newmarket pump produced larger tidal volumes but because of the small number of subjects this difference did not reach significance.

Figures $5 a$ and $5 b$ show changes in intracuirass pressure during the first two hours of sleep in patient No 14 on separate nights while using the Cape and Newmarket pumps respectively. Both pumps were adjusted to give a pressure of $30 \mathrm{~cm} \mathrm{H}_{2} \mathrm{O}$ inside the cuirass at the start of the night, but neither pump was adjusted thereafter. With the Cape pump the peak pressure achieved varied from breath to breath, with a range of $38-17 \mathrm{~cm} \mathrm{H}_{2} \mathrm{O}$; with the Newmarket pump the peak suction pressure varied much less, although there is a gradual fall in pressure in the initial stages from 30 to $26 \mathrm{~cm} \mathrm{H}_{2} \mathrm{O}$ as a result of temperature related drift of the pressure transducer.

The pump has been tested for longer periods under ordinary working conditions. At present we have 10 Newmarket pumps in use in patients' homes. Five have been in use for longer than six months. There have been no major problems and any minor adjustments have been made during routine admissions to hospital for reassessment.

\section{Discussion}

The Newmarket pump is both smaller and lighter than the Cape cuirass pump. It can conveniently be used in a small bedroom and patients can lift it into a car with minimal assistance, allowing them to travel. Both the pressure and the respiratory rate may be adjusted easily on the Newmarket pump by the patient to the optimal setting during assisted ventila-

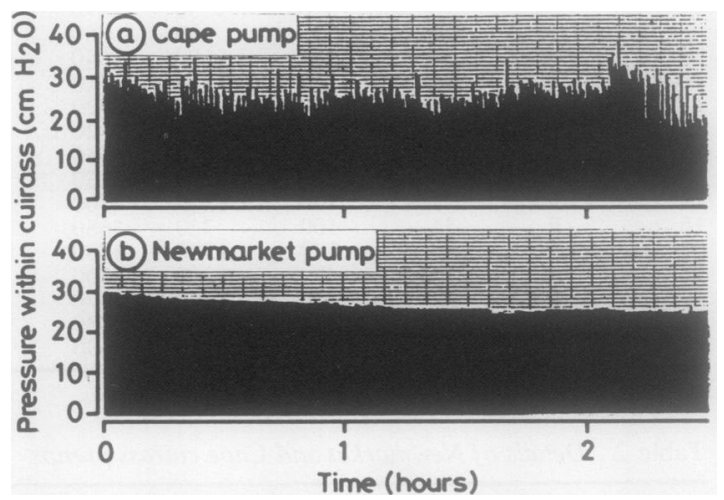

Fig 5 Variation of the peak pressure within the cuirass during the furst two hours of consecutive sleep studies in one patient, using (a) the Cape pump and (b) the Newmarket pump. 
tion. To change the pulley belt or alter the valve leak on the Cape pump requires considerable manual dexterity, a serious disadvantage in patients with skeletal deformities and muscle weakness who need the equipment.

The Newmarket pump used at a respiratory rate of 15 breaths per minute with an I:E ratio of $1: 1$ produced tidal volumes similar to those achieved with the Cape pump at 16 breaths per minute. The results were obtained with the patients awake and lying in one position in bed for a few minutes, during which time they were closely supervised. External negative pressure ventilation is, however, normally used overnight for several hours. Under these conditions there is air leakage between the cuirass shell and the patient, the amount of which depends on the position and movement of the patient during sleep. This air leakage can be minimised by careful construction of an individually tailored cuirass shell but it remains a considerable problem. The Cape pump is volume cycled and therefore unable to adapt accurately to a variable leak. This leads to a loss of pressure within the cuirass and consequent hypoventilation. There are therefore theoretical advantages in the use of a pressure cycled pump with a high flow capacity and an alarm to warn of low pressure. The Newmarket pump has these facilities.

The tidal volume achieved for any negative pressure produced round the thorax will depend on the time that the pressure is applied in each respiratory cycle and the compliance and the resistance of the respiratory system. In the group of patients we studied diseases of the chest wall, respiratory muscles, or airways almost certainly resulted in altered resistance and compliance of varying degrees, although these were not formally measured. The Cape pump has a fixed I:E ratio of $1: 2$ and the length of time the suction is applied to the chest cannot be increased. Slowing the respiratory rate lengthens the duration of inspiration of each breath, but the total time spent in inspiration over any period does not alter. With the Newmarket pump the duration of suction during each breath can be increased by increasing the $\mathrm{I}: \mathrm{E}$ ratio, and in patients with airflow obstruction the $\mathrm{I}: \mathrm{E}$ ratio may be decreased to minimise air trapping.

The pump has proved to be very satisfactory in service in the home. We believe that the portability and the accessible control panel of the Newmarket pump will make domiciliary external negative pressure ventilation acceptable to more patients, and that the ability of the pump to adjust to varying air leaks at night and to allow control of the I:E ratio will encourage more physicians to consider this method of ventilatory support.

We wish to thank Lorna Brown for assistance in making the cuirass shells. WJMK is supported by the Chest, Heart, and Stroke Association.

\section{References}

1 Weirs PWJ, Le Coultre R, Dallinga OT, Van Dijl W, Meinesz AF, Sluiter HJ. Cuirass respirator treatment of chronic respiratory failure in scoliotic patients. Thorax 1977;32:221-8.

2 Sawicka EH, Branthwaite MA, Spencer GT. Respiratory failure after thoracoplasty: treatment by intermittent negative-pressure ventilation. Thorax 1983;38: 433-5.

3 O'Leary J, King R, Leblanc M, Moss R, Liebhaber M, Lewiston $\mathbf{N}$. Cuirass ventilation in childhood neuromuscular disease. J Pediatr 1979;94:419-21.

4 Garay SM, Turino GM, Goldring RM. Sustained reversal of chronic hypercapnia in patients with alveolar hypoventilation syndromes. Am J Med 1981; 70:269-74.

5 Boutourline-Young HJ, Whittenberger JL. The use of artificial respiration in pulmonary emphysema accompanied by high carbon dioxide levels. J Clin Invest 1951;30:838-44. 